\title{
Effect of Sustained Subliminal Auditory Stimulus on Human Emotion
}

\author{
Ning Li, Liu Juan, Wang Xin, and Sun Xiang-hong
}

\begin{abstract}
Human cognition and emotion can be affected by subliminal visual stimulus. Does sustained subliminal auditory stimulus (SAS) have the similar effect? In this study, the speech sound "Be happier" was used as the SAS, and the power-to-take game was used as the experimental task to investigate the effect of SAS on human emotion. 34 subjects were randomly divided into control group and experiment group. SAS was the independent variable. Galvanic skin response (GSR), subjective ratings, and destruction in Power-to-Take game were the measurements. The results showed that SAS caused subjective feelings better $(p=0.039)$ and the decision making different $(p=0.027)$. The SAS can affect human emotion.
\end{abstract}

\section{INTRODUCTION}

Qubliminal visual stimulus can affect human cognition, Semotion and preference. The most commonly used paradigm is priming paradigm. Subliminal priming was firstly showed, then a mask showed, and the respondent stimulus showed after a short while of that. Researchers have found that subliminal visual words can enhance the persuasiveness of an ad targeting goal [1], subliminal visual motivation words contained in class PPT can affect students' academic performance moderated by mindfulness [2], and subliminal visual numbers can unconsciously manipulate human's free choice [3]. Human emotion and event-related potentials related to anxiety can be influenced by the subliminal words about emotion [4]. Also, the subliminal facial expression pictures can have the emotional effects [5].

There are also some researches about effect of SAS on cognition [6] and these researches were also using priming

Manuscript received November 20, 2010. This work was supported in part by Institute of Psychology, Chinese Academy of Science.

Sun Xiang-hong is with the Institute of Psychology, Chinese Academy of Sciences, Beijing, CO 100101, China (phone: 86-010-64837182; fax: 86-010-64837096; e-mail: sunxh@psych.ac.cn).

Ning Li is with the Institute of Psychology, Chinese Academy of Sciences and Graduate School of the Chinese Academy of Sciences, Beijing, CO 100101, China (e-mail: ningl@psych.ac.cn).

Liu Juan is with the Institute of Psychology, Chinese Academy of Sciences and Graduate School of the Chinese Academy of Sciences, Beijing, CO 100101, China (e-mail: liujuan@psych.ac.cn).

Wang xin is with the Institute of Psychology, Chinese Academy of Sciences and Graduate School of the Chinese Academy of Sciences, Beijing, CO 100101, China (e-mail: wangx@psych.ac.cn). paradigm. The subliminal sounds play simultaneously with the masking sounds, and the respondent stimulus shows after a short interval. There were few researches about effect of sustained SAS on human emotion.

This study investigates the effect of continuous subliminal auditory stimulus on human emotion. The Power-to-Take game was taken as the scenario to evoke the subjects' emotion. Two traditional measurements of emotion, subject evaluation and GSR were used. Since there is significant correlation between game destruction and experienced emotions [7], the destruction in Power-to-Take game was also the measurement.

In the two-person Power-to-Take Game, which is played only once and anonymously, both players receive equal endowments. One player (the take authority) has to decide first on how much money to take from the other player (the responder), that is, the take rate. Subsequently, after observing this take rate, responders have the option of destroying any percentage (from $0 \%$ to $100 \%$ ) of their own money. The money that is left after this destruction, together with the take rate, determines how much the take authority appropriates and what remains for the responder. Note that, for take rates greater than zero, the take authority will always end up with greater earnings than the responder [8].

In this study, we did some changes to the Power-to-Take game. The first was that we only have only one subject in each experiment, the other subject was pretended by the assistant. All of the subjects were designated to be the responder and the take rates to the subjects were controlled and the same. The second change was that, in order to make the effect of SAS stronger, we did four rounds of the game, instead of once.

\section{METHOD}

Participants were seated and received stimuli from the screen of a computer and the headset. Skin electric potential device was worn. Subjects were asked to play the power-to-take game and earn as more point as they can. Their task was to make the destruction decision. Four rounds of the game were taken and subject emotional scale was filled.

\section{A. Participants}

The 34 participants, 16 males and 18 females, recruited for this experiment were students and all of them 
had normal visual acuity (or corrected visual acuity) and normal hearing. The participants were between 20 and 26 years old. The age and gender distribution of the participants is provided in Table 1. Participants were paid according to their left points of the game, and were asked to sign an informed consent form before commencing testing. The whole test session lasted about $15 \mathrm{~min}$.

TABLE I.

CHARACTERIZATION OF PARTICIPANT GENDER, AGE AND NUMBER

\begin{tabular}{ccc}
\hline \hline Gender & Number & Average age(years) \\
\hline male & 16 & $22.94 \pm 1.81$ \\
female & 18 & $21.83 \pm 1.47$ \\
\hline \hline
\end{tabular}

\section{B. Experimental material}

A self-made program was used to show directions and record data. A computer installed with windows XP was used to run the experiment program. A multichannel physiologic recorder (MP) was used to record subjects' skin electric reaction. And a headset was used to play sounds to the subjects.

A Chinese subject emotional scale was used. This emotional scale includes two independent emotion dimensions, happiness and anger. The questions in this scale were chosen from an emotional scale made by Taiwan researcher Zhang Peizhen and Ye Yuzhu. The scale we used includes 20 questions. For each question, the participants have four choices: "very disagree", "somehow disagree", "somehow agree", and "very agree". The questions of the scale are listed in Table II.

TABLE II.

EMOTIONAL SCALE

\begin{tabular}{lll}
\hline \hline & \multicolumn{2}{c}{ Questions } \\
\hline Questions about & 1. & I feel content with my life now \\
happiness & 3. & I feel calm and relaxed \\
5. & I feel joyful \\
7. & I feel the word is nice \\
9. & I feel my life is full of happiness \\
13. & I feel lucky \\
14. & I feel happy \\
& 16. & I feel my life is full of hope \\
& 18. & I feel content \\
& 19. & I feel excited \\
& 20. & I feel spirited \\
& 2. & I feel disgusted with my everything \\
Questions about & 4. & I feel bad \\
anger & 6. & I feel crying \\
& 8. & I feel disappointed \\
10. & I feel angry \\
11. & I feel guilty \\
12. & I feel lonely \\
15. & I feel my life is miserable \\
17. & I feel annoyed \\
\hline \hline
\end{tabular}

Bandari's music Spring was the background music and voice sound "be happier" was the SAS. The difference of volume between the background music and SAS is $25 \mathrm{db}$. The SAS was played once a second. None of the participants reported the awareness of SAS.

\section{Experimental design}

The experiment was a between subject design. Every subject was asked to wear the headset and play the power-to-take game.

\section{1) Independent variables}

The experimental design included one between-subjects independent variable. The variable was subliminal auditory signal, including two levels: background music without subliminal signal and background music with subliminal auditory signal.

\section{2) Response method}

Subjects were told to earn more point as they can. That means, the destroy percentage should always be zero. But by the effect of emotion, the subjects made some destruction.

\section{3) Dependent variables}

Subject emotional feeling scale (including two dimensions, happy and angry), GSR (average skin electric level and four skin electric level of decision making time point) and the left point of Power-to-Take game (sum of the four rounds of game) were taken as the measurements. These three measures were all for assessing emotion.

\section{Experimental procedures}

The participants were randomly divided into two groups, each group included 17 members. Experiment group received the background music mixed with SAS and the control group received only background music. The experiment was conducted in standard behavior laboratory.

When subject came, a fake subject who was pretended by assistant showed. They were arranged into different rooms. Subjects were asked to sit in front of the computer, wear headset and MP, and have a rest. Music with SAS or without SAS began to play. Five minutes later, subjects were asked to start the game. Directions of the experiment and regulations of power-to-take game were shown on the screen. Subjects were told that the game would have four rounds, but the role would be designated only once, and the role would be designated randomly by the computer. After that, a choice should be done by the subjects to make sure they understood the game directions. Then, A "Waiting for the other participant" label showed on the screen and then "designating roles" label. All of the subjects were designated as responder.

In the first round of the game, subjects were taken $60 \%$ of their points. Subjects could make the decision of destruction percentage by typing the percentage in a text box. In the second round, subjects were taken $70 \%$. In the third round, subjects were taken $80 \%$. And in the fourth round, the take rate was $90 \%$. Experimenter sited beside the 
subjects and pressed F8 each time the participants made the decision to make a time point for the GSR analysis.

After four rounds of the game, the subject emotional feeling scale was shown. And the experiment was over after the scale having been done. Subjects were paid according to the left point of the game.

\section{RESULTS}

\section{A. Data processing}

One subject's data was excluded because he knew the fake subject. And the SPSS 15.0 statistical package was used for analysis.

\section{B. difference of the four rounds' decision}

Four rounds of the game were taken in order to enhance the effect of SAS. To test the sequence effect, repeated measures ANOVA was done. The result shows the difference of different round is not significant $(\mathrm{F}=0.914$, $\mathrm{p}=0.437$ ). That means the sequence effect of the four rounds is not significant.

TABLE III.

DESCRIPTIVE STATISTICS OF FOUR ROUNDS' DESTRUCTION PERCENTAGE $(\mathrm{N}=33)$

\begin{tabular}{llc}
\hline & \multicolumn{2}{c}{ Destruction percentage } \\
\cline { 2 - 3 } & Mean & SD \\
\hline Round 1 & 36.00 & 18.159 \\
Round 2 & 43.24 & 25.147 \\
Round 3 & 41.06 & 31.894 \\
Round 4 & 34.73 & 35.229 \\
\hline \hline
\end{tabular}

\section{C. interaction between independent variable and rounds}

To test the interaction between independent variable and rounds, a repeated measures general linear model analysis was done. Round was the within-subjects variable, experimental condition was the between-subjects factor. The main effect of experimental condition is significant $(\mathrm{F}=5.468, \mathrm{p}=0.026)$. The main effect of rounds $(\mathrm{F}=0.903$, $\mathrm{p}=0.443)$ and interaction $(\mathrm{F}=1.326, \mathrm{p}=0.271)$ are not significant.

TABLE IV.

DESCRIPTIVE STATISTICS OF DESTRUCT PERCENTAGE FOUR ROUND'S AND DIFFERENT EXPERIMENTAL CONDITION

\begin{tabular}{ccccc}
\hline \hline & \multicolumn{2}{c}{ experiment $(\mathrm{N}=17)$} & \multicolumn{2}{c}{ control $(\mathrm{N}=16)$} \\
\cline { 2 - 5 } & Mean & $\mathrm{SD}$ & Mean & $\mathrm{SD}$ \\
\hline Round 1 & 32.12 & 17.302 & 40.13 & 18.679 \\
Round 2 & 41.12 & 31.615 & 45.50 & 16.505 \\
Round 3 & 29.53 & 31.301 & 53.31 & 28.535
\end{tabular}

Round 4 24.18 30.208 45.94 37.604

\section{D. gender difference}

Subjects were randomly set into experiment group and control group, without counterbalance of gender. An independent sample $\mathrm{T}$ test was done to test the gender difference. The result shows the gender difference is significant $(\mathrm{t}=-2.057, \mathrm{p}=0.048)$. That means the female subjects destroyed less and left more points than the male subjects.

TABLE V.

\begin{tabular}{ccc} 
DESCRIPTIVE STATISTICS OF MALES’ AND FEMALES’ LEFT POINT \\
\cline { 2 - 3 } & \multicolumn{2}{c}{ Left point } \\
\cline { 2 - 3 } & Mean & SD \\
\hline male $(\mathrm{N}=15)$ & 54.600 & 14.5251 \\
female $(\mathrm{N}=18)$ & 66.339 & 17.6623 \\
\hline \hline
\end{tabular}

\section{E. the difference of left point between experiment and control}

The result above shows that there are differences between males and females. So gender was taken as the covariate. A univariate general linear model was done to test the difference of left point between experiment and control group. Experiment condition was the fixed factor and gender was the covariate. The left point was the dependent. Result shows that the experimental effect is significant $(\mathrm{F}=4.081, \mathrm{p}=0.027)$. That means the SAS can have some effect on human emotional behavior. The subliminal sounds "be happier" made the subjects more rational and destroy fewer points.

TABLE VI

DESCRIPTIVE STATISTICS OF EXPERIMENT GROUP AND CONTROL GROUP'S LEFT POINT

\begin{tabular}{llc}
\hline \hline & \multicolumn{2}{c}{ Left point } \\
\cline { 2 - 3 } & Mean & SD \\
\hline $\operatorname{Exp}(\mathrm{N}=17)$ & 66.494 & 19.2708 \\
$\operatorname{Con}(\mathrm{N}=16)$ & 55.169 & 12.6106 \\
\hline \hline
\end{tabular}

F. the difference of emotional scale between experiment and control

The two dimensions (happiness and anger) of the scale were analyzed independently. Two independent sample $t$ tests were done. The result shows that the happiness between experiment group and control group is significant $(\mathrm{t}=2.16, \mathrm{p}=0.039)$, but the anger is not significant $(\mathrm{t}=-0.457, \mathrm{p}=0.651)$. That means the subjects in 
experiment group was "happier", but the two groups' subjects were the same angry. The SAS "be happier" made the subjects happier, but didn't make them less angry.

TABLE VII.

RESULT OF MOTIONAL SCALE

\begin{tabular}{ccccc}
\hline & \multicolumn{2}{c}{$\exp (\mathrm{N}=17)$} & \multicolumn{2}{c}{ con $(\mathrm{N}=16)$} \\
\cline { 2 - 5 } & Mean & SD & Mean & SD \\
\hline Happiness & 34.94 & 2.861 & 33.13 & 1.821 \\
Anger & 14.82 & 3.321 & 15.38 & 3.612 \\
\hline \hline
\end{tabular}

\section{G. GSR}

GSR is the physiological reaction of emotion. In this study, four rounds' decision making time points' GSR and the average GSR of the whole duration of game were analyzed. The result shows that the difference of experiment group and control group is not significant. The possible reason is that the individual difference can be neglect.

TABLE VIII.

DESCRIPTIVE STATISTICS OF SKIN ELECTRIC REACTION

\begin{tabular}{|c|c|c|c|c|}
\hline & \multicolumn{2}{|c|}{ experiment $(\mathrm{N}=17)$} & \multicolumn{2}{|c|}{ control $(\mathrm{N}=16)$} \\
\hline & Mean & SD & Mean & SD \\
\hline Round 1 & 193452 & .380050771 & .06165643 & .150102798 \\
\hline Round 2 & .19017667 & .219895359 & .01791714 & .160324780 \\
\hline Round 3 & -.0079787 & 088816615 & .05452571 & .243902862 \\
\hline Round 4 & .07091400 & .173478711 & -.0042100 & .080881314 \\
\hline average & .01401600 & .009086928 & .01027429 & .018611960 \\
\hline
\end{tabular}

\section{CONCLUSIONS AND DISCUSSION}

Previous studies about subliminal perception were mainly focused on visual and using priming paradigm. In this study, we investigated the emotional effect of SAS, and the stimulus we used was continuous sounds. In four rounds of our games, we found there were no significant sequential effect and no interaction between independent variable and rounds. The gender difference is significant, males subjects tended to destroy more. So we can infer the male subjects were angrier in this game. Comparison between experiment group and control group showed that the subliminal sound "be happier" could make the subject destroy fewer points, and could make them happier through emotional scale, but couldn't make them less angry. The difference of GSR between experiment and control group was not significant, maybe because of the individual physiological difference of subjects.

In future study, we are going to investigate effect of different kinds of SAS and the mutual effect of subliminal visual stimulus and SAS. More kinds of SAS words should be used, for example, negative words. Mutual effect includes present SAS and subliminal visual stimulus at the same time.

\section{ACKNOWLEDGMENT}

The work described in this paper was sponsored by Institute of Psychology, Chinese Academy of Sciences. Thank Wang Xin and Liu Juan for their helps of doing experiments.

\section{REFERENCES}

[1] Erin J. Strahan, Steven J. Spencer, and Mark P. Zanna, "Subliminal priming and persuasion: Striking while the iron is hot," Journal of Experimental Social Psychology, vol. 38, pp. 556-568, Nov. 2002.

[2] Rémi Radel, Philippe Sarrazin, Pascal Legrain, Lucie Gobancé. "Subliminal priming of motivational orientation in educational settings: Effect on academic performance moderated by mindfulness," Journal of Research in Personality, vol. 43, pp. 695-698, Aug. 2009.

[3] Andrea Kiesel, Annika Wagener, Wilfried Kunde, Joachim Hoffmann, Andreas J. Fallgatter, Christian Stocker. "Unconscious manipulation of free choice in human," Consciousness and Cognition, vol. 15, pp. 397-408, Jun. 2006.

[4] Henning Gibbons. "Evaluative priming from subliminal emotional words: Insights from event-related potentials and individual differences related to anxiety," Consciousness and Cognition, vol. 18, pp. 383-400, Jun. 2009.

[5] Timothy D. Sweeny, Marcia Grabowecky, Satoru Suzuki, Ken A. Paller. "Long-lasting effects of subliminal affective priming from facial expressions," Consciousness and Cognition, vol. 18, pp. 929-938, Dec. 2009.

[6] Emmanuel Dupoux, Vincent de Gardellea, Sid Kouider. "Subliminal speech perception and auditory streaming," Cognition, vol. 109, pp. 267-273, Nov. 2008.

[7] Gershon Ben-Shakhar, Gary Bornstein, Astrid Hopfensitz, Frans van Winden. "Reciprocity and emotions in bargaining using physiological and self-report measures," Journal of Economic Psychology, vol. 28, pp. 314-323, Jun. 2007.

[8] Bosman, R., van Winden, F. "Emotional hazard in a power to take experiment," The Economic Journal, vol. 112, pp. 147-169, Jan. 2002. 